\title{
DESEMPENHO AMBIENTAL DE INSTITUIÇÕES FINANCEIRAS: UM ESTUDO COMPARATIVO ENTRE OS CINCO PRINCIPAIS BANCOS BRASILEIROS
}

\section{ENVIRONMENTAL PERFORMANCE OF FINANCIAL INSTITUTIONS: A COMPARATIVE STUDY AMONG TOP FIVE BRAZILIAN BANKS}

\author{
Marcelo Giroto Rebelato후 Amanda Zampieri de Almeida²; Andréia Marize Rodrigues ${ }^{3}$; \\ ${ }^{1}$ Universidade Estadual Paulista Júlio de Mesquita Filho - UNESP - Jaboticabal - SP - Brasil \\ mgiroto@fcav.unesp.br \\ ${ }^{2}$ Universidade Estadual Paulista Júlio de Mesquita Filho - UNESP - Jaboticabal - SP - Brasil \\ amanda_zalmeida@hotmail.com \\ ${ }^{3}$ Universidade Estadual Paulista Júlio de Mesquita Filho - UNESP - Jaboticabal - SP - Brasil \\ andreiamarize@fcav.unesp.br
}

\begin{abstract}
Resumo
O objetivo deste trabalho consiste em apresentar uma avaliação comparativa entre o desempenho ambiental dos cinco principais bancos brasileiros no período compreendido entre os anos 2009 a 2012. Para esta avaliação de desempenho utilizou-se como indicadores ambientais aqueles propostos pelas Diretrizes para Relatório de Sustentabilidade "Global Reporting Initiative" (GRI). Dentre os trinta indicadores de desempenho ambiental inicialmente identificados constatou-se que doze deles não são aplicáveis ao setor financeiro devido ao tipo de serviço prestado. Os dados para a pesquisa foram coletados a partir dos relatórios de sustentabilidade divulgados por cada banco. Os indicadores GRI aplicáveis foram ponderados utilizando-se o método Analytic Hierarchy Process (AHP), considerando que existe uma dominância de um elemento sobre outro. Os julgamentos necessários ao método AHP foram realizados por uma equipe de especialistas oriundos de duas universidades públicas paulistas. O teste de consistência mostrou que os valores atribuídos às prioridades relativas dos indicadores podem ser considerados consistentes. Como resultado final, sob a ótica da equipe de especilistas estabelecida, o Banco Bradesco foi o banco classificado em primeiro lugar com desempenho ambiental relativo de 100\%. Na segunda colocação o Banco Itaú, com desempenho ambiental relativo de 99,79\%. Em terceiro lugar o Banco do Brasil com desempenho relativo de 89,08\%. Na quarta posição o Banco Santander com desempenho relativo de 72,39\%. E em quinto e último lugar a CEF com desempenho relativo de 69,92\%. Conclui-se que os cinco principais bancos brasileiros possuem desempenho ambiental relativo que vai de "bom" a "muito bom".
\end{abstract}

Palavras-chave: desenvolvimento ambiental; indicadores ambientais; bancos; método Analytic Hierarchy Process (AHP).

\section{Introdução}

Há grande apreensão por parte da sociedade civil no tocante aos impactos ambientais imputados pelos propulsores do desenvolvimento econômico. A consciência da sociedade com 
relação a estes problemas e o arcabouço legal criado no mundo - e de forma bem avançada no Brasil - têm atingido também o sistema financeiro. Algumas organizações ligadas ao sistema financeiro e preocupadas com questões ambientais, como a Environmental Bankers Association (EBA), afirmam que atentar para o meio ambiente não é importante apenas sob a perspectiva de gerenciamento de risco, mas também representa uma abertura a novos negócios e pode tornar-se uma vantagem competitiva relevante (TOSINI, 2006a).

Por outro lado, evidenciar a obrigação com o resguardo do meio ambiente é também uma forma de assegurar o comportamento eticamente correto, abonando a boa reputação da empresa. Ademais, é um meio de afirmar publicamente a conduta confiável da instituição, legitimando a existência daquela atividade financeira. O comportamento cauteloso na avaliação dos impactos ambientais dos projetos postulantes a concessão de crédito tem também como raízes o "risco ambiental" a que a instituição financeira está submentida. Isto porque as instituições financeiras brasileiras não são protegidas legalmente contra imputações de responsabilidade civil ou criminal por danos ambientais causados pelos seus tomadores de crédito.

Não obstante, as instituições financeiras exercem um significante papel de impulsão e persuasão de práticas de sustentabilidade (MATTAROZZI \& TRUNKL, 2008), na medida em que realizam concessões de financiamentos a projetos economicamente vultosos, de grande importância social e com alto potencial de impacto no ambiente (INFANTE et al, 2010).

Neste panorama, as instituições bancárias, maiores protagonistas e articuladores do setor financeiro, possuem a função de captar dinheiro por meio dos depósitos executados por seus clientes (pessoas físicas, empresas, indústrias e governo) e reutilizá-lo para conceder empréstimos a outros clientes mediante o pagamento de juros. O resultado dessa função é a permanente circulação do capital no país gerando oportunidades e impulsionando o crescimento da economia. Os bancos concentram a maior parte da oferta de serviços financeiros, são responsáveis por $69,9 \%$ do total de empregos do setor e representam mais de 50\% do total de estabelecimentos (SANTOS et al, 2010; SEADE, 2014). Até o final do ano de 2012 o Brasil contava com aproximadamente 22.000 agências bancárias (BANCO CENTRAL DO BRASIL, 2013). Trata-se de um número expressivo, considerando que o país possui 5.570 municípios (PORTAL BRASIL, 2013), o que resulta em um número médio de quase quatro agências por município.

Os bancos têm desenvolvido ações relacionadas à avaliação de riscos ambientais em suas políticas de concessão de crédito, além de práticas internas para redução de resíduos e economia de energia (INFANTE et al, 2010). Além isso, os bancos têm divulgado o desempenho de suas práticas ambientais por meio de relatórios de sustentabilidade ambiental, sendo o Global Reporting Initiative (GRI) o relatório padronizado de maior destaque, entre as instituições, para a comunicação destes resultados. Ou seja, não basta apenas levar a cabo ações ambientais corretas. É 
preciso toná-las publicamente transparentes para que a sociedade possa ter entendimento sobre o desempenho geral e relativo de cada instituição.

Neste contexto, o objetivo deste trabalho é analisar comparativamente o desempenho ambiental dos cinco principais bancos brasileiros que publicam seus relatórios de sustentabilidade, que são Banco do Brasil, Banco Santander, Banco Bradesco, Banco Itaú e Caixa Econômica Federal (CEF), no período compreendido entre os anos 2009 a 2012.

É certo que a maior parte dos estudos centralizados no desempenho ambiental empresarial está concentrada em organizações extrativistas e fabris. Talvez pela circunstância do baixo impacto ambiental direto causado por meio das atividades exercidas pelo setor bancário, suas práticas ambientais não sejam adequada e suficientemente investigadas. Por conseguinte, o assunto tratado neste artigo é relevante na medida em que o setor bancário encerra grande impacto indireto no ambiente através de suas operações, principalmente por meio das atividades de financiamento. Ademais, o trabalho oferece uma valoração dos critérios utilizados no desenvolvimento da comparação relativa entre os bancos, contribuindo com a reflexão sobre a validade dos relatórios de sustentabilidade.

\section{Metodologia}

A presente pesquisa é de caráter descritivo e exploratório. Esse tipo de pesquisa é adequado às circunstâncias onde a investigação é realizada por meio de observações, registros, análise e correlações de dados em situações onde há pouco conhecimento sobre o assunto estudado (CERVO e BERVIAN, 1983).

O trabalho foi conduzido em seis etapas metodológicas, a saber:

a) Determinação dos indicadores ambientais - os indicadores ambientais utilizados para o desenvolvimento da análise comparativa foram aqueles propostos pelo modelo do relatório GRI. Em primeiro lugar, identificaram-se os indicadores presentes na estrutura GRI utilizáveis na elaboração de relatórios de sustentabilidade, em especial, os indicadores de desempenho ambiental. Foram identificados trinta indicadores de desempenho ambiental, designados EN1 a EN30 (GRI, 2006), os quais são divididos em conjuntos afins denominados como "aspectos", apresentados adiante;

b) Reconhecimento dos indicadores não aplicáveis - nem todos indicadores identificados na etapa anterior são aplicáveis às operações bancárias, de modo que os indicadores não são aplicáveis tiveram que ser expurgados;

c) Seleção das instituições bancárias e período de análise - os bancos selecionados foram os cinco maiores bancos brasileiros em relação ao lucro e patrimônio líquidos no período de 2009 a 2012 e que publicaram seus relatórios seguindo as diretrizes propostas pela GRI. Estes bancos 
foram tomados devido à sua relevância no panorama econômico do país (Tabela 1). O período escolhido (2009 a 2012) é justificado pelo fato de que neste os mesmos bancos se repetiram nas posições top em relação ao lucro e patrimônio líquidos. Apenas instituições que utilizam a metodologia GRI foram selecionadas porque somente desta maneira seria possível uma comparação fidedigna entre os relatórios. A lista dos bancos que apresentaram maior lucro e patrimônio líquido foi obtida através dos dados disponibilizados pelo Banco Central (BANCO CENTRAL DO BRASIL, 2013). Depois de selecionados os bancos, foram realizados cruzamento de dados entre os relatórios de sustentabilidade de cada instituição com as informações constantes no banco de dados da GRI;

Tabela 1 - Bancos brasileiros com maior lucro e patrimônio líquidos entre 2009 a 2012

\begin{tabular}{|c|c|c|c|}
\hline Ano & Banco & $\begin{array}{c}\text { Lucro líquido Anual } \\
\text { (em R\$ mil) }\end{array}$ & $\begin{array}{c}\begin{array}{c}\text { Patrimônio líquido } \\
\text { (em R\$ mil) }\end{array} \\
\end{array}$ \\
\hline \multirow{5}{*}{2009} & Banco do Brasil & 6.133 .961 & 36.119 .381 \\
\hline & Itaú & 5.480 .997 & 51.589 .860 \\
\hline & Bradesco & 4.042 .608 & 41.917 .596 \\
\hline & Caixa Econômica Federal & 1.842 .183 & 13.143 .767 \\
\hline & Santander & 826.641 & 64.936 .705 \\
\hline \multirow{5}{*}{2010} & Itaú & 6.955 .703 & 61.802 .220 \\
\hline & Banco do Brasil & 6.626 .909 & 50.495 .589 \\
\hline & Bradesco & 5.526 .841 & 48.218 .521 \\
\hline & Caixa Econômica Federal & 2.096 .727 & 15.436 .950 \\
\hline & Santander & 1.883 .717 & 65.322 .455 \\
\hline \multirow{5}{*}{2011} & Itaú & 7.530 .018 & 72.528 .414 \\
\hline & Banco do Brasil & 6.050 .743 & 58.592 .586 \\
\hline & Bradesco & 5.549 .595 & 55.767 .699 \\
\hline & Caixa Econômica Federal & 2.908 .217 & 19.561 .381 \\
\hline & Santander & 1.783 .676 & 66.122 .836 \\
\hline \multirow{5}{*}{2012} & Itaú & 6.948 .886 & 82.825 .221 \\
\hline & Banco do Brasil & 6.835 .222 & 66.350 .927 \\
\hline & Bradesco & 5.763 .247 & 70.236 .524 \\
\hline & Caixa Econômica Federal & 3.219 .706 & 25.056 .944 \\
\hline & Santander & 1.347 .324 & 66.470 .335 \\
\hline
\end{tabular}

Fonte: BANCO CENTRAL DO BRASIL, (2013)

d) Coleta dos dados - para a coleta de dados foi utilizada pesquisa documental em base secundária de dados. Os dados foram coletados a partir dos relatórios de sustentabilidade divulgados por cada banco;

e) Ponderação relativa entre os aspectos e os indicadores ambientais - nesta etapa priorizaram-se as importâncias relativas de cada "aspecto" e cada indicador ambiental GRI considerando sua aplicação no âmbito das instituições de serviços bancários. Conforme Saaty (2010), a priorização envolve o desenvolvimento de julgamentos em resposta às questões de dominância de um elemento sobre outro quando comparados com relação a certa propriedade. Neste percurso, utilizou-se o método Analytic Hierarchy Process (AHP), uma ferramenta flexível que é preparada para levar em conta os diversos critérios para o processo de decisão (SAATY, 1991). O AHP é um método que permite a manipulação dos fatores intangíveis de julgamento de maneira 
simples e compreensível, sendo adequado a problemas de definição de prioridades, avaliação de custos x benefícios, alocação de recursos, benchmarking, analise de decisão sob-riscos, entre outros (SAATY, 2008). Para a aplicação dos julgamentos necessários ao método AHP, uma equipe de especialistas foi selecionada por conveniência. Esta equipe foi composta por cinco profissionais ligados à pesquisa universitária em áreas de gestão ambiental e pertencentes a duas universidades públicas paulistas;

f) Análise comparativa entre os bancos - com o desdobramento do método AHP, iniciado na etapa anterior, chegou-se naturalmente à comparação entre o desempenho ambiental dos cinco bancos. O desempenho de cada indicador ambiental de cada banco foi analisado a partir de dados objetivos. Foi realizado a partir do nível de atendimento do indicador conforme informação divulgada pelo banco. Desta forma, seguindo a lógica AHP, para cada subcritério de comparação, ou seja, para cada indicador ambiental, comparou-se o desempenho dos bancos entre si, paritariamente. As conclusões qualitativas finais foram realizadas a partir do desempenho relativo de cada banco conforme a Tabela 2.

Tabela 2 - Referência de julgamento qualitativo final para as instituições bancárias

\begin{tabular}{|c|c|}
\hline Desempenho relativo & Avaliação qualitativa \\
\hline $100 \%-80 \%$ & Muito bom \\
\hline $80 \%-60 \%$ & Bom \\
\hline $60 \%-40 \%$ & Regular \\
\hline $40 \%-20 \%$ & Ruim \\
\hline $20 \%-0 \%$ & Muito ruim \\
\hline
\end{tabular}

Fonte: Autoria própria (2014)

\section{Global Reporting Initiative (GRI)}

A Global Reporting Initiative é uma organização não governamental internacional fundada em 1997 com sede na Holanda, que desenvolve diretrizes para elaboração de relatórios de sustentabilidade, os quais atualmente estão na sua terceira geração. Ela surgiu para oferecer uma estrutura confiável para a elaboração dos relatórios de maneira que possa ser utilizada por organizações de todos os tamanhos, setores e localidades (GRI, 2006).

A Figura 1 mostra como deve ser a estrutura dos relatórios da GRI. O que relatar pode ser encontrado nos itens de conteúdo do relatório e nos suplementos setoriais. Os suplementos setoriais complementam as diretrizes com orientações de como aplicá-los a determinados setores e trazem indicadores específicos para cada setor. A maneira de relatar está disponível nos princípios e orientações e nos protocolos técnicos. 


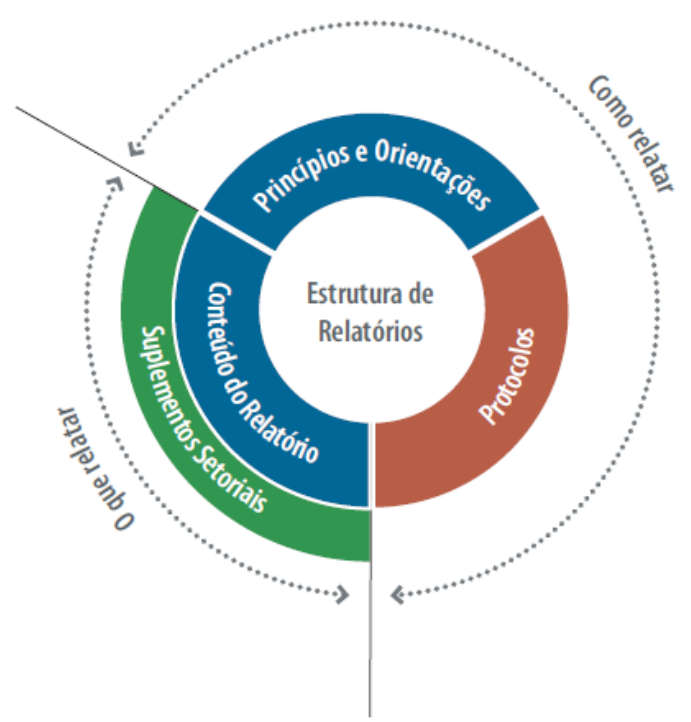

Fonte: GRI (2006, p.3)

$\mathrm{Na}$ elaboração do relatório de sustentabilidade primeiramente deve-se definir o que será relatado, os limites de abrangência, determinar os temas e os indicadores a serem divulgados. Segundo a GRI, o relatório deve apresentar o perfil, a forma de gestão e os indicadores de desempenho da organização. O perfil deve conter informações tais como a estratégia organizacional, o perfil e a governança. No tocante à forma de gestão, a organização deve descrever a maneira como ela trata determinados temas como ambienais, sociais e econômicos. Os indicadores de desempenho trazem informações comparáveis sobre o desempenho econômico, ambiental e social da organização (GRI, 2006).

Depois de finalizado o relatório a empresa deve declarar o nível de aplicação da estrutura de relatórios através do sistema de níveis de aplicação da GRI. Isso é importante tanto para os usuários do relatório quanto para os relatores. Para os usuários, traz clareza sobre até que ponto foram aplicadas as diretrizes. Para os relatores, oferece auxílio na expansão da aplicação das diretrizes durante o decorrer dos anos. São três os níveis de aplicação nomeados por "C", "B” e "A". Quanto maior o nível de aplicação da estrutura de relatórios, mais próximo de "A" é a classificação. A organização também pode se autodeclarar um ponto a mais em cada nível se for utilizada verificação externa (por exemplo, “C+", "B+" ou "A+"). Além de se autodeclarar, ela pode utilizar verificação externa obtendo um parecer em relação à sua autodeclaração ou ainda solicitar à GRI que examine a autodeclaração.

Conforme GRI (2006), a dimensão ambiental da sustentabilidade se refere aos impactos da organização sobre sistemas naturais vivos e não vivos, incluindo ecossistemas, terra, ar e água. Os indicadores ambientais GRI abarcam o desempenho relacionado a insumos (como material, energia, água) e a produção (emissões, efluentes, resíduos). Além disso, abrangem o desempenho relativo à 
biodiversidade, à conformidade ambiental e outras informações relevantes, tais como gastos com meio ambiente e os impactos de produtos e serviços. Os indicadores ambientais GRI são agrupados em conjuntos afins chamados de "aspectos", os quais podem ser vistos na Tabela 3.

Tabela 3 - Aspectos e indicadores ambientais propostos pela GRI

\begin{tabular}{|c|c|}
\hline Aspecto & Indicadores de desempenho ambiental \\
\hline \multirow{2}{*}{ Materiais } & EN1 Materiais usados por peso ou volume \\
\hline & EN2 Percentual dos materiais usados provenientes de reciclagem \\
\hline \multirow{5}{*}{ Energia } & EN3 Consumo de energia direta discriminada por fonte de energia primária \\
\hline & EN4 Consumo de energia indireta discriminada por fonte primária \\
\hline & EN5 Energia economizada devido a melhorias em conservação e eficiência \\
\hline & $\begin{array}{l}\text { EN6 Iniciativas para fornecer produtos e serviços com baixo consumo de energia, ou que usem } \\
\text { energia gerada por recursos renováveis, e a redução na necessidade de energia resultante dessas } \\
\text { iniciativas }\end{array}$ \\
\hline & EN7 Iniciativas para reduzir o consumo de energia indireta e as reduções obtidas \\
\hline \multirow{3}{*}{ Água } & EN8 Total de retirada de água por fonte \\
\hline & EN9 Fontes hídricas significativamente afetadas por retirada de água \\
\hline & 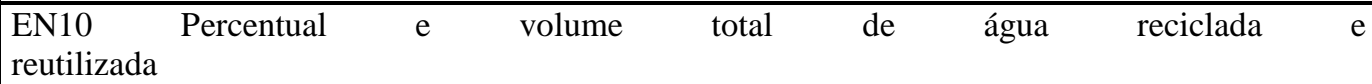 \\
\hline \multirow{5}{*}{ Biodiversidade } & $\begin{array}{l}\text { EN11 Localização e tamanho da área possuída, arrendada ou administrada dentro de áreas } \\
\text { protegidas, ou adjacentes a elas, e áreas de alto índice de biodiversidade fora das áreas protegidas }\end{array}$ \\
\hline & $\begin{array}{l}\text { EN12 Descrição de impactos significativos na biodiversidade de atividades, produtos e serviços } \\
\text { em áreas protegidas e em áreas de alto índice de biodiversidade fora das áreas protegidas }\end{array}$ \\
\hline & EN13 Habitats protegidos ou restaurados \\
\hline & $\begin{array}{l}\text { EN14 Estratégias, medidas em vigor e planos futuros para a gestão de impactos na } \\
\text { biodiversidade }\end{array}$ \\
\hline & $\begin{array}{l}\text { EN15 Número de espécies em listas nacionais de conservação com habitats em áreas afetadas } \\
\text { por operações, discriminadas pelo nível de risco de extinção }\end{array}$ \\
\hline \multirow{10}{*}{$\begin{array}{l}\text { Emissões, } \\
\text { efluentes e } \\
\text { resíduos }\end{array}$} & $\begin{array}{l}\text { EN16 É um indicador essencial, mas no caso do setor financeiro sugere-se comentário } \\
\text { relacionado às emissões de gases de efeito estufa em viagens de negócios }\end{array}$ \\
\hline & EN17 Outras emissões indiretas relevantes de gases de efeito estufa, por peso \\
\hline & $\begin{array}{llcllll}\text { EN18 } & \text { Iniciativas } & \text { para } & \text { reduzir } & \text { as } & \text { emissões } & \text { de } \\
\text { efeito estufa e as reduções obtidas } & & & & & \\
\end{array}$ \\
\hline & EN19 Emissões de substâncias destruidoras da camada de ozônio, por peso \\
\hline & EN20 NOx, SOx e outras emissões atmosféricas significativas, por tipo e peso \\
\hline & EN21 Descarte total de água, por qualidade e destinação. \\
\hline & $\begin{array}{l}\text { EN22 É um indicador essencial, mas no caso do setor financeiro sugere-se comentário para } \\
\text { especificar que os principais tipos de resíduos das instituições financeiras são papel e lixo } \\
\text { eletrônico }\end{array}$ \\
\hline & EN23 Número e volume total de derramamentos significativos \\
\hline & $\begin{array}{l}\text { EN24 Peso de resíduos transportados, importados, exportados ou tratados considerados } \\
\text { perigosos e percentuais de carregamentos de resíduos transportados internacionalmente }\end{array}$ \\
\hline & $\begin{array}{l}\text { EN25 Identificação, tamanho, status de proteção e índice de biodiversidade de corpos d'água e } \\
\text { habitats relacionados significativamente afetados por descartes de água e drenagem realizados } \\
\text { pela organização relatora }\end{array}$ \\
\hline \multirow{2}{*}{ Produtos e serviços } & $\begin{array}{l}\text { EN26 Iniciativas para mitigar os impactos ambientais de produtos e serviços e a extensão da } \\
\text { redução desses impactos }\end{array}$ \\
\hline & $\begin{array}{l}\text { EN27 Percentual de produtos e suas embalagens recuperadas em relação ao total de produtos } \\
\text { vendidos, por categoria de produto }\end{array}$ \\
\hline
\end{tabular}




\begin{tabular}{|c|c|}
\hline Conformidade & $\begin{array}{l}\text { EN28 Valor monetário de multas significativas e número total de sanções não monetárias } \\
\text { resultantes da não conformidade com leis e regulamentos ambientais }\end{array}$ \\
\hline Transporte & $\begin{array}{l}\text { EN29 Impactos ambientais significativos do transporte de produtos e outros bens e materiais } \\
\text { utilizados nas operações da organização, bem como do transporte de trabalhadores }\end{array}$ \\
\hline Geral & $\begin{array}{lccccc}\text { EN30 } & \text { Total } & \text { de } & \text { investimentos } & \text { e } & \text { gastos } \\
\text { ambiental, por tipo } & & & & \\
\end{array}$ \\
\hline
\end{tabular}

Fonte: Adaptado de GRI (2006)

O aspecto "materiais" engloba os indicadores EN1 e EN2. O indicador EN1 diz respeito ao consumo de materiais utilizados por peso ou volume. Por meio deste identifica-se o total de materiais utilizados (matérias-primas, materiais associados ao beneficiamento, peças semi fabricadas, materiais para embalagens). Em seguida os materiais devem ser classificados em materiais não renováveis e materiais diretos (estão presentes no produto final) e o peso ou volume dos materiais deve ser relatado. Essas informações podem ser obtidas junto aos sistemas de faturamento ou no departamento de gestão de suprimentos. O indicador EN2 mostra o percentual de materiais usados provenientes de reciclagem. Para calcular este indicador deve-se identificar o peso ou volume total de materiais utilizados e dividi-lo pelo peso ou volume de insumos reciclados. As informações podem ser obtidas da mesma maneira que as informações do indicador EN1.

O aspecto "energia" é composto pelos indicadores EN3, EN4, EN5, EN6 e EN7. O indicador EN3 mede o consumo de energia direta pela organização discriminando por fonte de energia primária. Para obter este indicador é necessário identificar as fontes de energia primária compradas pela organização (podendo ser renováveis ou não renováveis), as fontes de energia direta produzidas e as fontes de energia direta vendidas. Assim, o consumo de energia é igual a soma da energia comprada e da energia produzida menos a energia vendida. Essas informações podem ser obtidas através de faturas, notas de entrega e medição do combustível utilizado. O indicador EN4 mede o consumo de energia indireta discriminada por fonte primária e fornece informações sobre o consumo de energia necessário para a produção de energia comprada externamente. O indicador é calculado identificando a quantidade de energia intermediária comprada e consumida de fontes externas classificando-as em energias renováveis e não renováveis. Depois deve ser identificada a quantidade consumida de combustíveis primários para produzir energia intermediária com base no total de energia comprada de fornecedores. Isso pode ser obtido através de dados junto ao fornecedor de energia. O indicador EN5 mostra a energia economizada resultante de melhorias em conservação e eficiência. Deve ser considerada a economia proveniente de redesenho de processo, modernização de equipamentos e mudanças de comportamento dos empregados. Os dados podem ser obtidos através de medições internas de energia bem como de fornecedores de energia. $\mathrm{O}$ indicador EN6 mostra as iniciativas para fornecer produtos e serviços com baixo consumo de energia. Nele devem ser relatas as iniciativas para reduzir o consumo de energia em produtos ou serviços importantes. As reduções durante o período de cobertura do relatório devem ser 
quantificadas. Os dados podem ser obtidos através de medições de produtos internos, pesquisas sobre padrões de uso. O indicador EN7 mostra as iniciativas para reduzir o consumo de energia indireta e as reduções obtidas. Na quantificação deve ser excluído o consumo de energia indireta relacionado à compra de energia intermediária, pois ele já é considerado no indicador EN4. Devem ser relatas as iniciativas para redução do consumo de energia em relação ao uso de materiais com alto consumo de energia, produção terceirizada, viagens de negócios e transporte de empregados. A redução do consumo de energia durante o período de cobertura do relatório deve ser quantificada. Os dados necessários podem ser obtidos através de fornecedores e cálculos de ciclo de vida.

O aspecto "água” é composto pelos indicadores EN8, EN9 e EN10. O indicador EN8 mede o consumo de água e para tanto deve ser relatado o volume total de água retirada em metros cúbicos por ano e deve ainda ser discriminado por fontes (água de superfície, água subterrânea, água de chuva). As informações podem ser obtidas através de medidores de água e contas de água.O indicador EN9 mede os impactos relacionados ao uso da água e para isso deve-se primeiramente identificar e relatar o número total de fontes de água significativamente afetadas pela retirada de água e deve ser indicado o tamanho da fonte em metros cúbicos e se a fonte é ou não designada como área protegida. As informações podem ser obtidas junto a ministérios ou departamentos de governos responsáveis por questões relacionadas à água e estudos de impactos ambientais. $\mathrm{O}$ indicador EN10 mede o percentual e volume total de água reciclada e reutilizada considerando tanto água tratada como água não tratada antes da reutilização. Deve ser relatado o volume total de água reciclada e reutilizada e o percentual em relação ao volume de água consumida (indicador EN8).

O aspecto "biodiversidade" é composto pelos indicadores EN11, EN12, EN13, EN14 e EN15. O indicador EN11 mede o tamanho da área possuída dentro de áreas de proteção legal ou que tenham alto índice de biodiversidade. As informações podem ser obtidas através dos contratos de compra e venda e com órgãos públicos responsáveis por conservação e proteção ambiental. O indicador EN12 descreve os impactos significativos na biodiversidade nas áreas identificadas no indicador EN11. Deve ser relatada a natureza dos impactos (construção ou uso de fábricas e minas, infraestrutura de transportes, poluição, introdução de espécies invasoras, redução de espécies, conversão de habitat) bem como os impactos significativos em relação às espécies afetadas, extensão das áreas impactadas, duração dos impactos, reversibilidade ou irreversibilidade dos impactos. As informações podem ser encontradas no sistema de gestão ambiental da organização relatora. O indicador EN13 mede a eficiência de estratégias específicas para prevenir e reparar impactos negativos em áreas protegidas. Para tanto deve ser relatado o tamanho e a localização de todas as áreas protegidas ou restauradas em hectares e se o resultado das medidas de restauração foi aprovado por especialistas externos. As informações podem ser obtidas no sistema de gestão ambiental da organização. O indicador EN14 mostra as medidas em vigor e planos futuros para a 
gestão de impactos na biodiversidade. A política de gestão da biodiversidade deve conter estratégias para estudos de impactos ambientais locais, metodologia para determinar a exposição da biodiversidade a riscos, estabelecer metas e objetivos específicos, monitorar as ações e deve ainda elaborar relatórios públicos. O indicador EN15 identifica onde as atividades da organização podem trazer risco a espécies de fauna e flora quase ameaçadas, vulneráveis, ameaçadas ou criticamente ameaçadas de extinção.

O aspecto "emissões, efluentes e resíduos" é composto pelos indicadores EN16, EN17, EN18, EN19, EN20, EN21, EN22, EN23, EN24 e EN25. O indicador EN16 mede o total de emissões diretas e indiretas de gases de efeito estufa (GEE) em toneladas equivalentes de $\mathrm{CO}_{2}$. Pelo fato de existirem várias metodologias para calcular o volume de emissões de GEE, a organização deve indicar o padrão usado e a metodologia associada aos dados. Devem ser calculadas as emissões de todas as fontes de energia diretas e indiretas. As emissões podem ser calculadas a partir de dados dos indicadores EN3 e EN4. O indicador EN17 mede as emissões indiretas relevantes de gases de efeito estufa por peso. Devem ser excluídas as emissões indiretas constantes no indicador EN16 e identificadas as emissões de gases resultantes do uso indireto de energia como por exemplo transporte de empregados e frota de carros blindados terceirizados. As informações necessárias para compilação do indicador podem ser obtidas com informações de fornecedores externos. O indicador EN18 mostra as iniciativas para reduzir as emissões de GEE e as reduções obtidas. Ele deve ser utilizado em conjunto com os indicadores EN16 e EN17 indicando as reduções de emissão fazendo a distinção entre as reduções obrigatórias e as reduções voluntárias. O indicador EN19 mede as emissões de substâncias destruidoras da camada de ozônio, tais como CFC, hidrocarboneto halogenado e brometo de metila. Elas devem ser relatadas em toneladas. O indicador EN20 mede as emissões de NOx, SOx e outras emissões atmosféricas significativas por tipo e peso. Devem ser relatados os pesos de emissões atmosféricas significativas em quilogramas ou seus múltiplos para NOx, SOx, poluentes orgânicos persistentes, compostos orgânicos voláteis, poluentes atmosféricos perigosos, emissões de chaminé e fugitiva, material particulado e outras categorias conforme a necessidade da organização. A metodologia utilizada para os cálculos deve ser indicada. O indicador EN21 mede o descarte total de água por qualidade e destinação. Deve ser relatado o volume total de descartes planejados e não planejados de água em metros cúbicos por ano discriminado por destinação, método de tratamento e se foi reutilizado por outra organização. Neste caso, deve ser excluída a água coletada de chuva e esgoto doméstico. O indicador EN22 mede o peso total de resíduos, por tipo e método de disposição. Deve ser identificada a quantidade, em toneladas, de resíduos gerados pela organização separando-os em resíduos perigosos e resíduos não perigosos. Depois, deve ser relatada a destinação dos resíduos sendo os seguintes métodos: compostagem, reutilização, reciclagem, recuperação, incineração, aterro sanitário, injeção 
subterrânea ou armazenamento no local. O indicador EN23 mostra o número e volume total de derramamentos de substâncias químicas, óleos e combustíveis. Deve ser relatada a localização dos derramamentos, o volume e o material derramado. O indicador EN24 indica o peso dos resíduos perigosos transportados. Ele deve ser indicado em quilos ou toneladas separando-os em resíduos transportados, importados, exportados e tratados. O indicador EN25 traz informações qualitativas para os indicadores quantitativos de descarte de água, pois nele devem ser identificados os corpos d'água significativamente afetados por descartes e devem ser incluídas informações acerca do tamanho do corpo d'água em metros cúbicos, se a fonte é uma área protegida e o valor da biodiversidade no local.

O aspecto "produtos e serviços" é composto pelos indicadores EN26 e EN27. O indicador EN26 mostra as iniciativas para reduzir os impactos ambientais de produtos e serviços e a extensão da redução dos impactos. Devem ser descritas as iniciativas em relação ao uso de materiais, uso de água, emissões, efluentes, poluição sonora e resíduos emitidos. Deve ser relatado quantitativamente até que ponto as iniciativas foram efetivas na redução dos impactos ambientais durante o período coberto pelo relatório. O indicador EN27 identifica o percentual de produtos e embalagens recuperados em relação à quantidade vendida por categoria de produto dentro do período de cobertura do relatório. Ele permite avaliar até que ponto os produtos e componentes são coletados e convertidos em materiais úteis para novos processos e também, até que ponto a organização projetou produtos e embalagens capazes de serem reutilizados ou reciclados. É importante que seja relatado como os dados foram coletados.

O aspecto "conformidade" conta apenas com o indicador EN28. Ele mostra multas significativas e sanções não monetárias em termos de valor monetário total, números de sanções não monetárias e processos movidos através de mecanismos de arbitragem.

O aspecto "transporte" também possui apenas um indicador, o EN29. Este indicador mostra os impactos ambientais significativos resultantes dos meios de transporte utilizados pela organização para fins logísticos e para o transporte do público interno. Devem ser indicados os critérios e metodologias usadas para determinar quais impactos ambientais são significativos e quando os dados quantitativos não forem declarados deve ser divulgada a razão.

O aspecto "geral" possui o indicador EN30 que mostra o total de investimentos e gastos em proteção ambiental por tipo. Devem ser identificados os custos de disposição de resíduos, tratamento de emissões e de mitigação, custos de prevenção, de gestão ambiental e despesas totais de proteção ambiental. 


\section{O impacto ambiental das operações bancárias}

CONAMA (1986) define impacto ambiental como qualquer alteração das propriedades físicas, químicas e biológicas do meio ambiente, causada por qualquer forma de matéria ou energia resultante das atividades humanas que, direta ou indiretamente, afetam: a saúde, a segurança e o bem-estar da população; as atividades sociais e econômicas; a biota; as condições estéticas e sanitárias do meio ambiente; a qualidade dos recursos ambientais.

Embora a atividade financeira não seja, ela própria, de grande impacto ambiental, os bancos em menor escala, são também poluidores (TOSINI, 2006b). Os bancos consomem energia, água, papel, cartuchos de toner e eletrônicos, sendo estes quatro últimos materiais recicláveis. Note-se que o consumo de energia nas operações bancárias é considerado, entre todos, como o fator de maior impacto ambiental (BISANG, 2000).

Entretanto, sem fazer parte de qualquer tipo de operação extrativista ou manufatureira, e sem fornecer serviços e produtos de impacto significativo direto no meio ambiente, o setor financeiro não é considerado de alto impacto ambiental. Na verdade, o índice FTSE4Good da Bolsa de Valores de Londres classifica o setor na categoria de médio impacto, e na literatura acadêmica ele é tido como de baixo impacto ambiental. Contudo, embora o setor não possua um alto impacto direto, seu impacto indireto, por meio de suas atividades de financiamento, é considerável, e seu papel como agente estimulador do desenvolvimento sustentável vem ganhando crescente reconhecimento mundialmente (LINS \& WAJNBERG, 2007).

Como ações de desenvolvimento sustentável por parte setor bancário, podem-se citar os financiamentos de infraestrutura ambiental, tais como fornecimento de água tratada e tratamento de resíduos líquidos (efluentes) e resíduos sólidos, disposição de resíduos perigosos, construção de hidrelétricas e de estradas, os quais são empreendimentos de forte impacto ambiental. Os bancos também podem financiar novas tecnologias que possam ajudar a resolver problemas ambientais. Nesta vertente, podem ter bons retornos financiando a recuperação de propriedades contaminadas (brown-fields) ou o desenvolvimento de métodos produtivos inteligentes em novas plantas (greenfields) (TOSINI, 2005). Na área de energia, os bancos podem financiar a produção de energia limpa e renovável, tanto como compensação ao seu elevado consumo de energia como em função de receitas adicionais relativas à venda de créditos de carbono. Uma iniciativa de grande reconhecimento no setor foi a construção, em 2003, da Usina Termoelétrica Bandeirantes, a maior usina de biogás do mundo e a primeira do Brasil, através da parceria entre o Unibanco, Biogás Energia Ambiental e Eletropaulo. A usina produz biogás a partir do gás metano liberado pelo Aterro Bandeirantes, gerando mais de $170.000 \mathrm{MW} / \mathrm{h}$ por ano, abastecendo prédios administrativos do Unibanco e comunidades do entorno (LINS \& WAJNBERG, 2007). 
Dado que todo o poluidor é obrigado, independentemente de existência de culpa, a reparar os danos causados ao meio ambiente e a terceiros, efetuados por sua atividade, os bancos podem minimizar os impactos financeiros de um desastre ambiental por meio do seguro ambiental. Com o seguro a empresa contratante passa a contar com cobertura caso a sua propriedade contenha depósitos desconhecidos com elementos poluidores ou, eventualmente, se descubra que o terreno de sua propriedade já fora agredido anteriormente por substâncias nocivas à saúde. A proteção do seguro abrange poluição através do descarte, dispersão, liberação ou o escape de qualquer elemento irritante, poluente ou contaminador, sólido, líquido, gasoso ou térmico, inclusive, mas não limitado a fumaça, vapores, fuligem, exalações, produtos químicos ácidos, alcalinos, tóxicos, resíduos hospitalares e materiais de refugos, dentro do ou sobre o solo, ou em qualquer estrutura sobre o solo, na atmosfera ou em qualquer curso d'água ou em outros elementos aquáticos, inclusive lençóis freáticos, entre outros, desde que essas condições não estejam naturalmente presentes no meio ambiente, nas quantidades ou concentrações descobertas. Ao contratar o seguro ambiental, as empresas passam a ter um mecanismo imediato para disponibilidade de valores para resolver questões que vão, por exemplo, recompor a empresa (se houve um acidente é porque existiu uma falha com danos materiais, provavelmente); ajudar a comunidade do entorno da empresa, dar uma satisfação a ela e ressarcir as perdas decorrentes do acidente (MERCADO COMUM, 2014).

Outros exemplos oferecidos pelos grandes bancos brasileiros incluem financiamentos para projetos de substituição de combustível líquido por gás natural, financiamentos para aquisição de veículos para pessoas com deficiências e financiamentos para o plantio de eucalipto para pequenos produtores rurais (e a consequente proteção de reservas nativas). Cinco dos dez maiores bancos oferecem linhas de financiamento com essas características, embora não tenham sido encontrados dados sobre a rentabilidade destes produtos (LINS \& WAJNBERG, 2007).

Por outro lado, a legislação brasileira contempla a responsabilidade solidária de todos aqueles que, de algum modo, participaram ou concorreram, direta ou indiretamente, para a prática do dano ambiental. Quando se fala em responsabilidade solidária, é irrelevante a alegação de ausência de acordo, de vontade, unidade de desígnios entre as partes, pois tais aspectos são indiferentes à espécie. Pela solidariedade, todos aqueles que de alguma forma contribuem para a conduta, como o caso das instituições financeiras mediante a concessão de financiamentos, mesmo que de forma indireta, respondem pelos danos causados pela atividade dos financiados. Contudo, a análise não é simples, já que, o financiador exige da empresa a comprovação dos requisitos necessários para conceder o crédito, inclusive aqueles de ordem ambiental (licença prévia, licença de instalação e licença de funcionamento), além da declaração dos órgãos responsáveis, os quais atestam que a empresa está em situação regular perante o ambiente (BLANK \& BRAUNER, 2009; BEAL, 2011). 
O banco nacional de Desenvolvimento Econômico e Social (BNDES), por exemplo, está sofrendo processo como corresponsável por dano ambiental causado pela mineradora CMM. Se ficar comprovado que, no curso da ação ordinária, que a empresa financiadora, mesmo ciente dos danos ambientais que se mostraram sérios e graves houver liberado parcelas intermediárias ou finais dos recursos para o projeto de exploração minerária da dita empresa, caber-lhe-á responder solidariamente pelos danos causados ao ambiente (TOSINI, 2005).

Há ainda outra forma de responsabilização das instituições bancárias. Esta se refere ao financiamento imobiliário em áreas contaminadas. O banco que financiar um projeto envolvendo uma área contaminada também assume a responsabilidade sobre o passivo ambiental. Pode-se citar aqui o artigo 13 da Lei 13.577/2009, em que são considerados responsáveis legais e solidários pela remediação de uma área contaminada não apenas o causador da contaminação, mas também seus sucessores, o proprietário da área e quem dela se beneficiar direta ou indiretamente (FEBRABAN, 2013).

\section{O método AHP}

A estruturação de um problema AHP se inicia com o estabelecimento do objetivo desejado. A partir desse definem-se os critérios numa estrutura em árvore invertida (Figura 2), sendo o objetivo principal a raiz desta árvore. À medida que se afasta da raiz, tem-se os fatores mais específicos (as “folhas”), os quais representam os critérios de avaliação. Para cada grupo de critérios semelhantes que possuem um mesmo "pai”, uma matriz de comparações paritárias (MCP), contendo os níveis de anteposição obtidos por confrontação de um fator com outro, deve ser construída. O princípio do AHP é a geração de um vetor de prioridades pelo cálculo do maior autovetor de cada MCP do problema inteiro (SHIMIZU, 2010).

Figura 2 - Estrutura de decisão hierárquica no método AHP

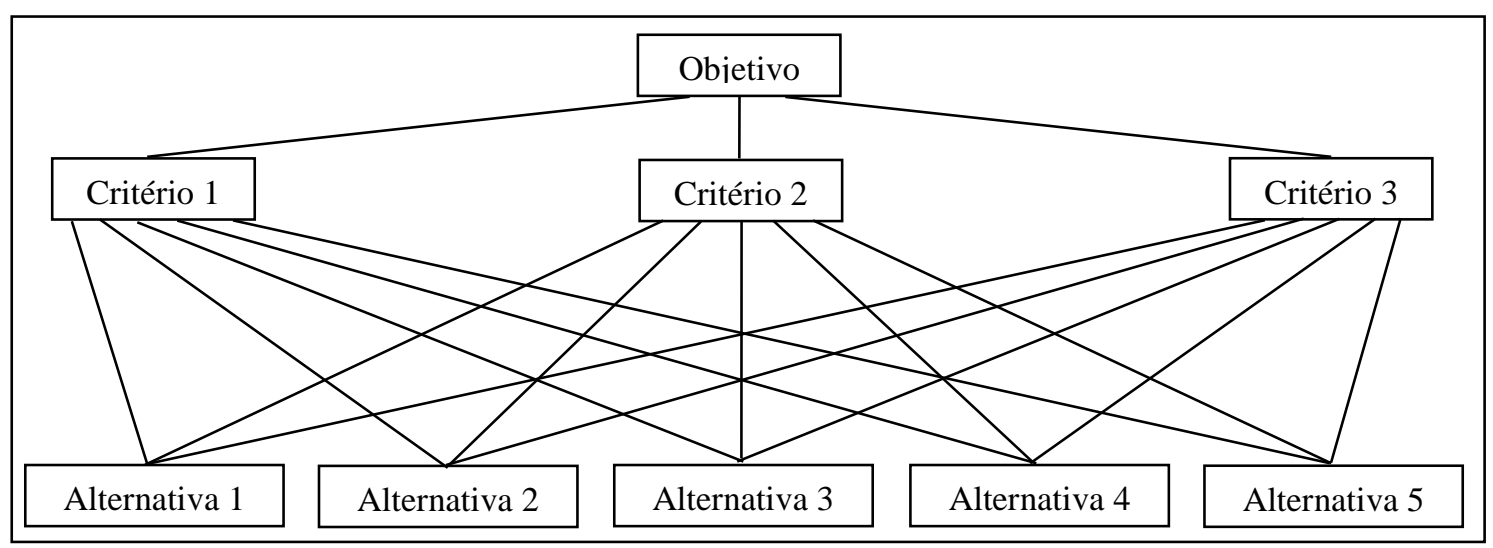

Fonte: Autoria própria (2014). 
As comparações paritárias não são feitas em escala absoluta devido à condição dos componentes de uma decisão múlti critérios. Dado que frequentemente o problema é impalpável, isso impede que isoladamente os componentes sejam mensurados usando a mesma escala. $\mathrm{Na}$ comparação paritária, quando o tomador de decisão manifestar sua preferência por um atributo X, como sendo muito mais importante do que o atributo $\mathrm{Y}$, por exemplo, estará atribuindo para o atributo $\mathrm{X}$ peso 5. Caso o tomador de decisão considere que os dois critérios possuem a mesma importância, estará atribuindo o peso 1. A Tabela 4 define e explica o conceito dos pesos utilizados no método AHP (OLIVEIRA et al, 2011).

Tabela 4 - Fatores do AHP para as comparações paritárias

\begin{tabular}{|c|c|c|}
\hline $\begin{array}{c}\text { Intensidade de } \\
\text { importância } \\
\text { (peso) }\end{array}$ & Peso & Explicação \\
\hline 1 & Mesma importância & Os dois atributos contribuem igualmente para o objetivo \\
\hline 3 & $\begin{array}{c}\text { Importância pequena de um } \\
\text { sobre o outro }\end{array}$ & $\begin{array}{c}\text { A experiência e o julgamento favorecem levemente um atributo } \\
\text { em relação ao outro }\end{array}$ \\
\hline 5 & $\begin{array}{c}\text { Importância grande ou } \\
\text { essencial }\end{array}$ & $\begin{array}{c}\text { A experiência e o julgamento favorecem fortemente um atributo } \\
\text { em relação ao outro }\end{array}$ \\
\hline 7 & Importância muito grande & $\begin{array}{c}\text { Um atributo é fortemente favorecido em relação ao outro; sua } \\
\text { dominação de importância é demonstrada na prática. }\end{array}$ \\
\hline 9 & Importância absoluta & $\begin{array}{c}\text { A evidência favorece um atributo em relação ao outro com o } \\
\text { mais alto grau de certeza }\end{array}$ \\
\hline $2,4,6,8$ & $\begin{array}{c}\text { Valores intermediários entre } \\
\text { os valores adjacentes }\end{array}$ & $\begin{array}{c}\text { Quando se procura uma condição de compromisso entre duas } \\
\text { definições }\end{array}$ \\
\hline
\end{tabular}

Fonte: OLIVEIRA et al (2011, p.6)

Saaty (1991) e Naves (2008) apresentam a modelagem matemática do AHP. Dado que A seja uma MCP genérica, n(n-1)/2 é o número de julgamentos paritários necessários à construção de A, onde n é o número de elementos da matriz. Nesta, $\mathrm{a}_{\mathrm{ij}}$ indica o julgamento quantificado do par de critérios $\left(\mathrm{C}_{\mathrm{i}}, \mathrm{C}_{\mathrm{j}}\right)$ e $\alpha$ o valor da intensidade de importância. Os elementos de A são:

$$
A=\left[\begin{array}{cccc}
1 & a_{12} & \cdots & a_{1 n} \\
1 / a_{12} & 1 & \cdots & a_{2 n} \\
\vdots & \vdots & \vdots & \vdots \\
1 / a_{1 n} & 1 / a_{2 n} & \cdots & 1
\end{array}\right]
$$

Se $\mathrm{a}_{\mathrm{ij}}=\alpha$, então $\mathrm{a}_{\mathrm{ji}}=1 / \alpha, \alpha \neq 0$.

Se $C_{i}$ é julgado como de igual importância relativa a $C_{j}$, então $a_{i j}=1$, $a_{i j}=1$ e $a_{i i}=1$, para todo i.

Normaliza-se A por meio da Equação1:

$$
\mathrm{Vi}(\mathrm{aj})=\frac{\text { aij }}{\sum_{i=1}^{n} \text { aij }}
$$


Onde: $\mathrm{n}=$ numero de alternativas comparadas;

Vi $\left(\mathrm{a}_{\mathrm{j}}\right)=$ valor normalizado, obtido dividindo os valores das colunas pela soma dos valores das colunas.

Em seguida, calcula-se o vetor de prioridade $W$ da alternativa i em relação ao critério $C_{k}$ e determina-se a média de cada linha dos valores normalizados (Equação 2).

$$
\mathrm{W}=\mathrm{Vk}(\mathrm{Ai})=\sum_{\mathrm{j}=1}^{\mathrm{n}} \overline{\mathrm{V} i} \frac{\overline{\mathrm{Aj}}}{\mathrm{n}}
$$

Onde: $\mathrm{W}$ ou Vk $(\mathrm{Ai})=$ Vetor de prioridades.

Então, calcula-se o autovalor $\left(\lambda_{\max }\right)$ por meio da Equação 3:

$$
\lambda \max =\frac{1}{n} \sum_{i=1}^{n} \frac{(\text { Aw }) \mathrm{i}}{\text { wi }}
$$

Onde: $\lambda_{\max }=$ autovalor procurado;

$\mathrm{W}=$ vetor de prioridades;

$\mathrm{Aw}=$ vetor resultante entre matriz A multiplicado pelo vetor de prioridades.

Em seguida, calcula-se o Índice de Consistência (IC) por meio da Equação 4:

$$
\mathrm{IC}=(\lambda \max -\mathrm{n}) /(\mathrm{n}-1)
$$

Onde: $\lambda_{\max }=$ autovalor procurado.

O próximo passo é o cálculo da Razão de Consistência (Equação 5):

$$
\mathrm{RC}=\frac{\mathrm{IC}}{\mathrm{CA}}
$$

Onde: CA é o índice de consistência aleatória (CA), apresentado na Tabela 5.

Tabela 5 - Valores de CA em Função da Ordem da Matriz

\begin{tabular}{|c|c|c|c|c|c|c|c|c|c|c|c|c|c|c|c|}
\hline $\mathbf{n}$ & 1 & 2 & 3 & 4 & 5 & 6 & 7 & 8 & 9 & 10 & 11 & 12 & 13 & 14 & 15 \\
\hline $\mathbf{C A}$ & 0,00 & 0,00 & 0,58 & 0,90 & 1,12 & 1,24 & 1,32 & 1,41 & 1,45 & 1,49 & 1,51 & 1,48 & 1,56 & 1,57 & 1,59 \\
\hline
\end{tabular}

Fonte: Saaty (1991, p.27)

Considera-se aceitável uma razão de consistência menor que 0,10 .

Por fim, determina-se o nível de preferência das alternativas. Estas devem ser comparadas par a par em cada um dos critérios, de modo análogo ao descrito para a obtenção da importância relativa dos critérios. Efetua-se a valoração global de cada uma das alternativas, de acordo com a expressão (Equação 6): 


$$
V(a)=\sum_{j=1}^{n} \operatorname{pjvj(a)}
$$

Onde: $\mathrm{V}$ (a) corresponde ao valor global da alternativa analisada;

pj à importância relativa do critério j;

vj ao nível de preferência da alternativa analisada no critério j.

\section{Resultados e discussão}

Primeiramente, o conjunto completo de indicadores ambientais foi analisado para que se expurgassem os indicadores não aplicáveis ao setor financeiro. Dentre os trinta indicadores, dezoito foram considerados aplicáveis e doze foram considerados não aplicáveis como mostra a Figura 3. Os indicadores classificados como não aplicáveis foram: EN9, EN11, EN12, EN13, EN14, EN15, EN19, EN20, EN23, EN24, EN25 e EN27.

Figura 3 - Percentual de indicadores aplicáveis

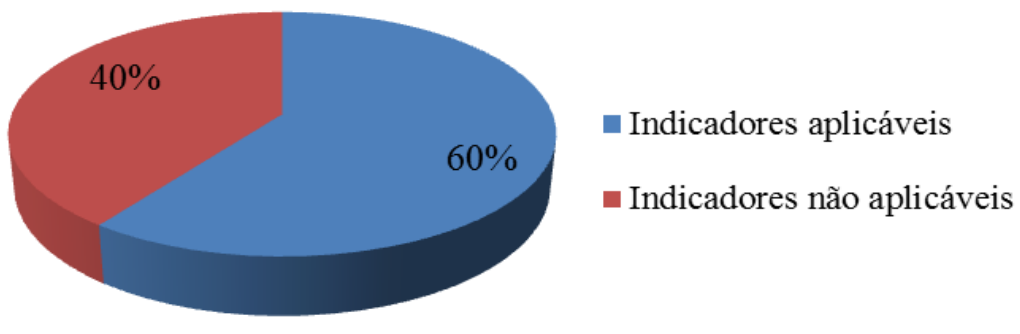

Fonte: Autoria própria (2014)

O indicador EN9 (fontes hídricas significativamente afetadas por retirada de água) relata fontes hídricas significativamente afetadas por retirada de água, porém toda a água utilizada nas instituições analisadas vem da rede de abastecimento pública.

Todos os indicadores do aspecto "biodiversidade" (EN11 ao EN15) foram considerados não aplicáveis porque as unidades bancárias são localizadas em áreas urbanas. A única exceção foi relatada pelo banco Santander, que possui uma agência em Fernando de Noronha. No relatório de 2009 a empresa relatou a obtenção da certificação ISO 14000 para as atividades de manutenção predial, limpeza, segurança, controle de pragas e gestão predial da agência.

Os indicadores EN19 (emissão de substâncias destruidoras da camada de ozônio) e EN20 (NOx, SOx e outras emissões atmosféricas) foram considerados não aplicáveis porque eles tratam de emissões de substâncias destruidoras da camada de ozônio e emissões de NOx e SOx e estas emissões são nulas ou não significativas no caso de instituições financeiras. 
$\mathrm{O}$ indicador EN23 (número de volume total de derramamentos) não foi considerado aplicável porque as atividades não envolvem uso significativo de substâncias químicas, óleos ou combustíveis.

O indicador EN24 (peso de resíduos transportados, importados, exportados ou considerados perigosos) não se aplica porque os bancos não transportam produtos considerados perigosos. $\mathrm{O}$ indicador EN25 (identificação de áreas significativamente afetadas por descartes de água) não foi considerado aplicável porque os descartes de água são feitos em rede pública de esgoto.

O EN27 (percentual de produtos e embalagens recuperadas em relação à quantidade vendida) foi considerado não aplicável, pois ele diz respeito ao percentual de produtos e embalagens recuperadas em relação à quantidade vendida e isso não acontece no caso de bancos pelo fato deles venderem serviços. No entanto, apesar de ser considerado não aplicável o banco Itaú, no relatório de 2010, mostrou algumas iniciativas neste sentido. O banco possui um programa que tem por finalidade recolher pilhas, baterias e equipamentos eletrônicos quebrados ou sem uso. Os itens coletados são destinados a empresas especializadas parceiras do projeto responsáveis pelo tratamento, reciclagem e reaproveitamento dos materiais.

A partir do acima exposto, verifica-se que o aspecto biodiversidade não mais comparece. Dessa forma, a hierarquia AHP final com objetivo, critérios, subcritérios e alternativas pode ser vista na Figura 4.

Figura 4 - Hierarquia final AHP para avaliação do desempenho dos bancos

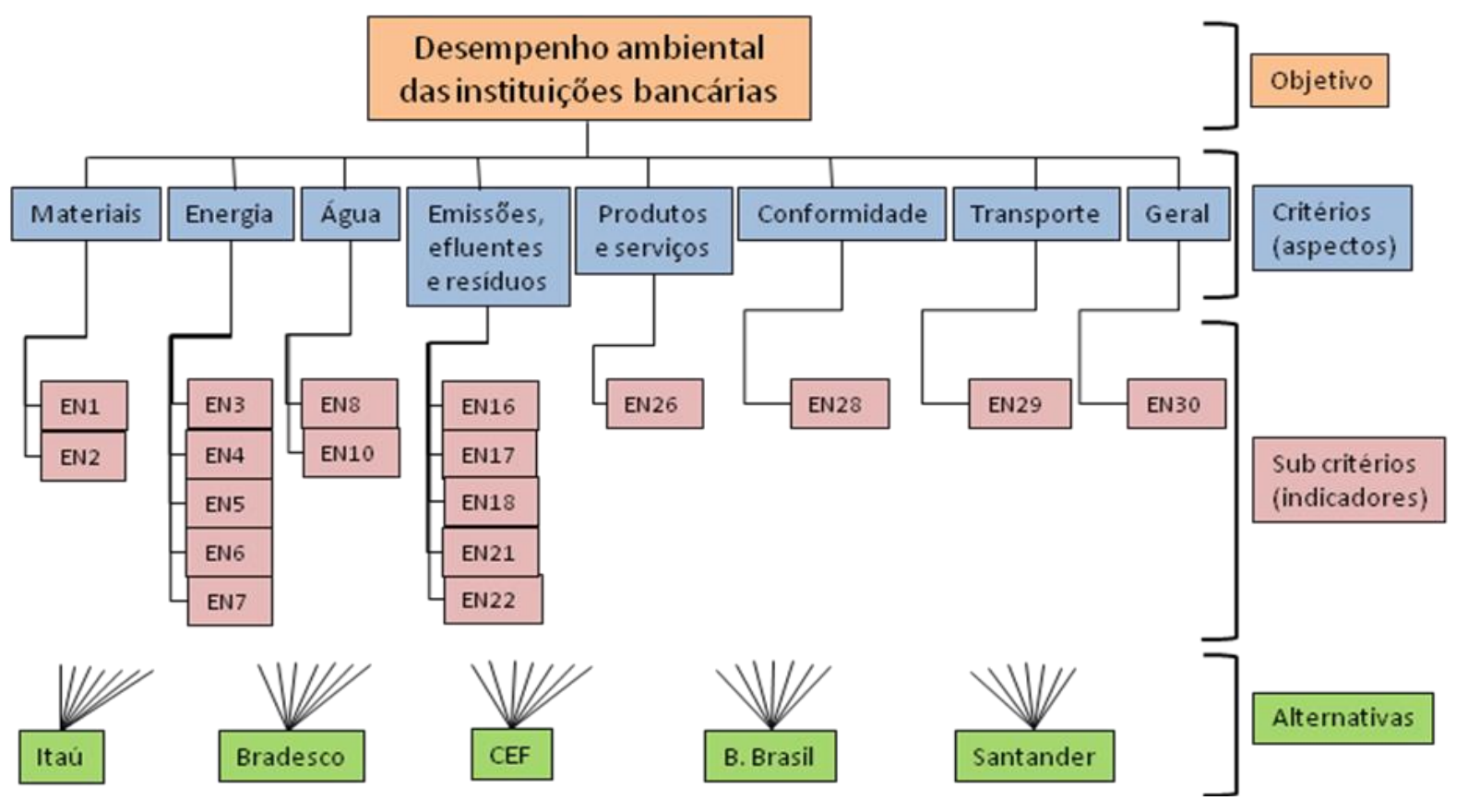

Fonte: Autoria própria (2014)

Em um segundo momento, cada membro da equipe de especialistas selecionada confrontou, em pares, todos os oito "aspectos" (critérios) do relatório ambiental GRI, utilizando para isso o 
balizamento oferecido pela Tabela 4. Os dados de cada preferência, de cada avaliador, foram introduzidos no software citado. Este calculou a média das avaliações feitas por cada membro da equipe, para cada critério, e exibiu o resultado da ponderação relativa conforme apresentado na Figura 5.

Figura 5 - Resultado da avaliação para grau de importância relativa de cada critério

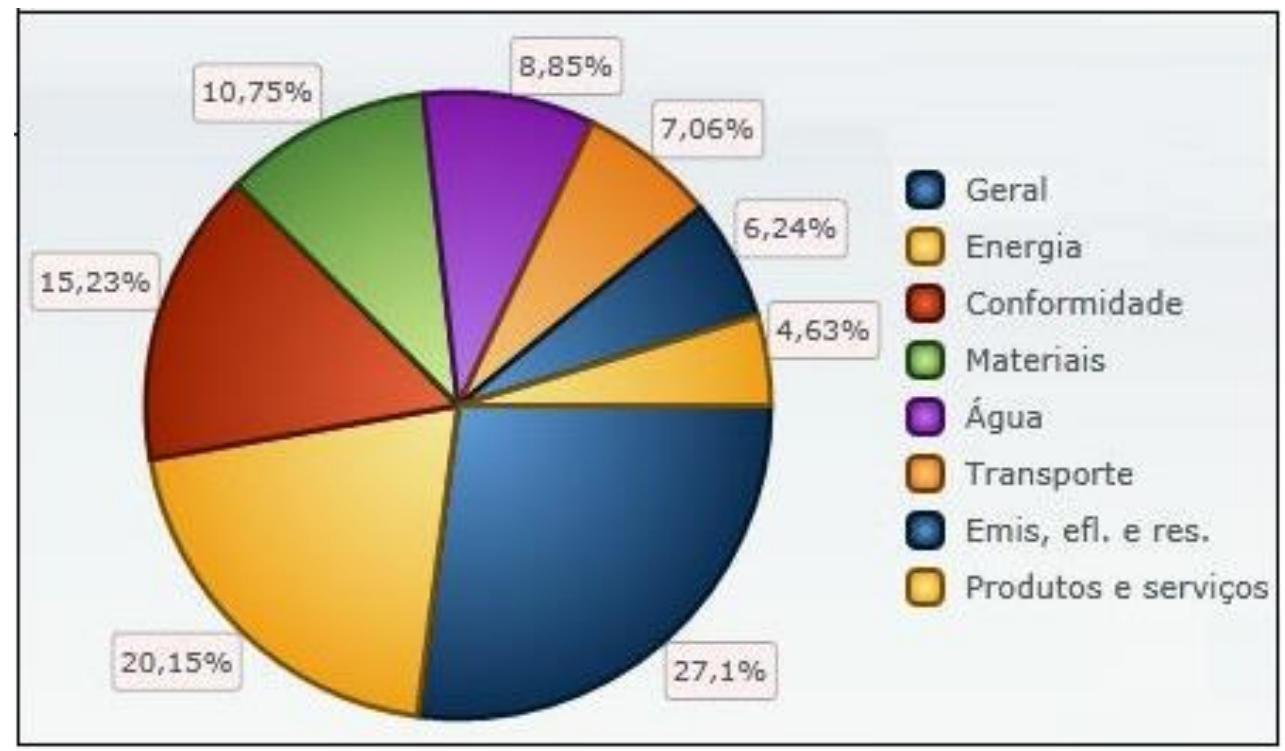

Fonte: Autoria própria (2014)

Conforme a Figura 5, o total de investimentos e gastos em proteção ambiental (critério "geral") foi considerado o critério de maior importância relativa $(27,10 \%)$, pois se julgou como inconteste o alto impacto ambiental das atividades de financiamento executadas pelas instituições bancárias no Brasil. Em segundo lugar classificou-se o critério "energia" (20,15\%), pois se trata do recurso de maior impacto ambiental direto entre todos os outros os recursos necessários à sua operação. Em terceiro lugar, categorizou-se o critério "conformidade" (15,23\%), dado que os bancos estão sujeitos a financiamentos de projetos importantes, porém que podem revelar-se posteriormente causadores de poluição ou danos ao meio ambiente. Mesmo na condição de poluidores indiretos, por regra de solidariedade, os bancos estão sujeitos à responsabilização, o que pode gerar penalidades legais. Em quarto lugar veio o critério "materiais" (10,75\%). Os bancos são grandes consumidores de papel e, mesmo com o aumento no uso da informática, a utilização de papel é crescente. Neste aspecto também se considerou o consumo de eletrônicos e toners de impressão. Em quinto lugar foi classificado o critério "água" (8,85\%), destacando-se que este critério foi considerado de baixo impacto, pois os bancos não consomem água para atividades produtivas como o fazem as indústrias. Em sexto lugar, com pouca expressão relativa, classificou-se o critério "transporte" (7,06\%). Os bancos utilizam o transporte apenas para movimentação de valores e pessoal. Na sétima posição e oitava posições foram categorizados os critérios "emissões, efluentes e resíduos" (6,24\%) e "produtos e serviços" (4,62\%) respectivamente, pois os bancos 
emitem poucos resíduos, os quais são todos recicláveis ou tratáveis e não produzem produtos tangíveis de qualquer tipo.

Analogamente à ponderação relativa entre os critérios, a equipe confrontou, dois a dois, os indicadores considerados aplicáveis (subcritérios). Posteriormente, cada membro da equipe contrastou, paritariamente, cada uma das cinco alternativas (bancos) relativamente a cada um dos dezoito indicadores aplicáveis: EN1, EN2, EN3, EN4, EN5, EN6, EN7, EN8, EN10, EN16, EN17, EN18, EN21, EN22, EN26, EN28, EN29, EN30.

Conforme Saaty (1991), uma taxa ou razão de consistência de 0,10 ou menos é considerada aceitável. Foi calculada, neste caso, uma Razão de Consistência RC =0,047. Sendo assim, os valores das prioridades relativas foram julgados consistentes.

Como pode ser visto pela exibição em forma de gráfico polar na Figura 6, os Bancos Bradesco e Itaú apresentaram resultados de desempenho ambiental muitos próximos em todos os aspectos considerados, sendo que as suas curvas estão praticamente sobrepostas. Através do gráfico de barras apresentado na Figura 7 e também por meio da Tabela 6, verifica-se que o Banco Bradesco foi o banco classificado em primeiro lugar com desempenho ambiental relativo de $100 \%$. Em todos os aspectos avaliados o Banco Bradesco teve desempenho máximo. Conforme Tabela 2, seu desempenho ambiental pode ser classificado como "muito bom". Em segundo lugar classificouse o Banco Itaú, com desempenho ambiental relativo de 99,79\%, uma diferença de apenas 0,21\% entre o primeiro e o segundo colocado. Avalia-se como "muito bom” o resultado para o Banco Itaú. Em terceiro lugar figura o Banco do Brasil com desempenho relativo de 89,08\%, para o qual se pode notar desempenho um pouco mais baixo nos aspectos energia, água e emissões, efluentes e resíduos. O desempenho qualitativo do Banco do Brasil pode ser avaliado como "muito bom”. Em quarto lugar aparece o Banco Santander com desempenho relativo de 72,39\%, para o qual se pode notar desempenho um pouco mais baixo nos aspectos energia, água, emissões, efluentes e resíduos, produtos e serviços e conformidade. O desempenho qualitativo do Banco Santander pode ser avaliado como "bom". Em quinto e último lugar figura a CEF com desempenho relativo de 69,92\%, para a qual se pode notar desempenho um pouco mais baixo nos aspectos materiais, energia, água, emissões, efluentes e resíduos, produtos e serviços e conformidade. O desempenho qualitativo da CEF pode ser avaliado como "bom". 
Figura 6 - Resultado da comparação entre os cinco bancos em gráfico polar

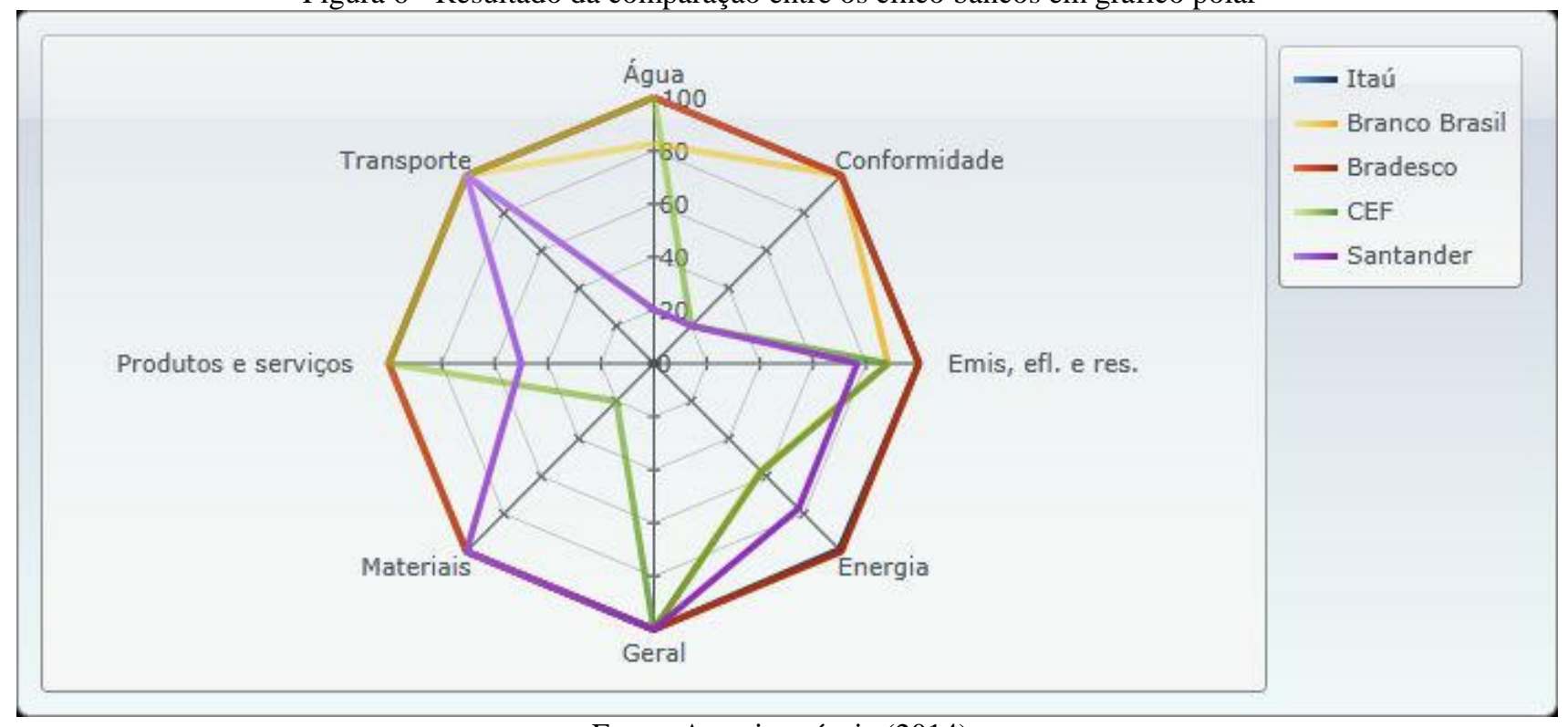

Fonte: Autoria própria (2014)

Figura 7 - Resultado da comparação entre os cinco bancos em gráficos de barras

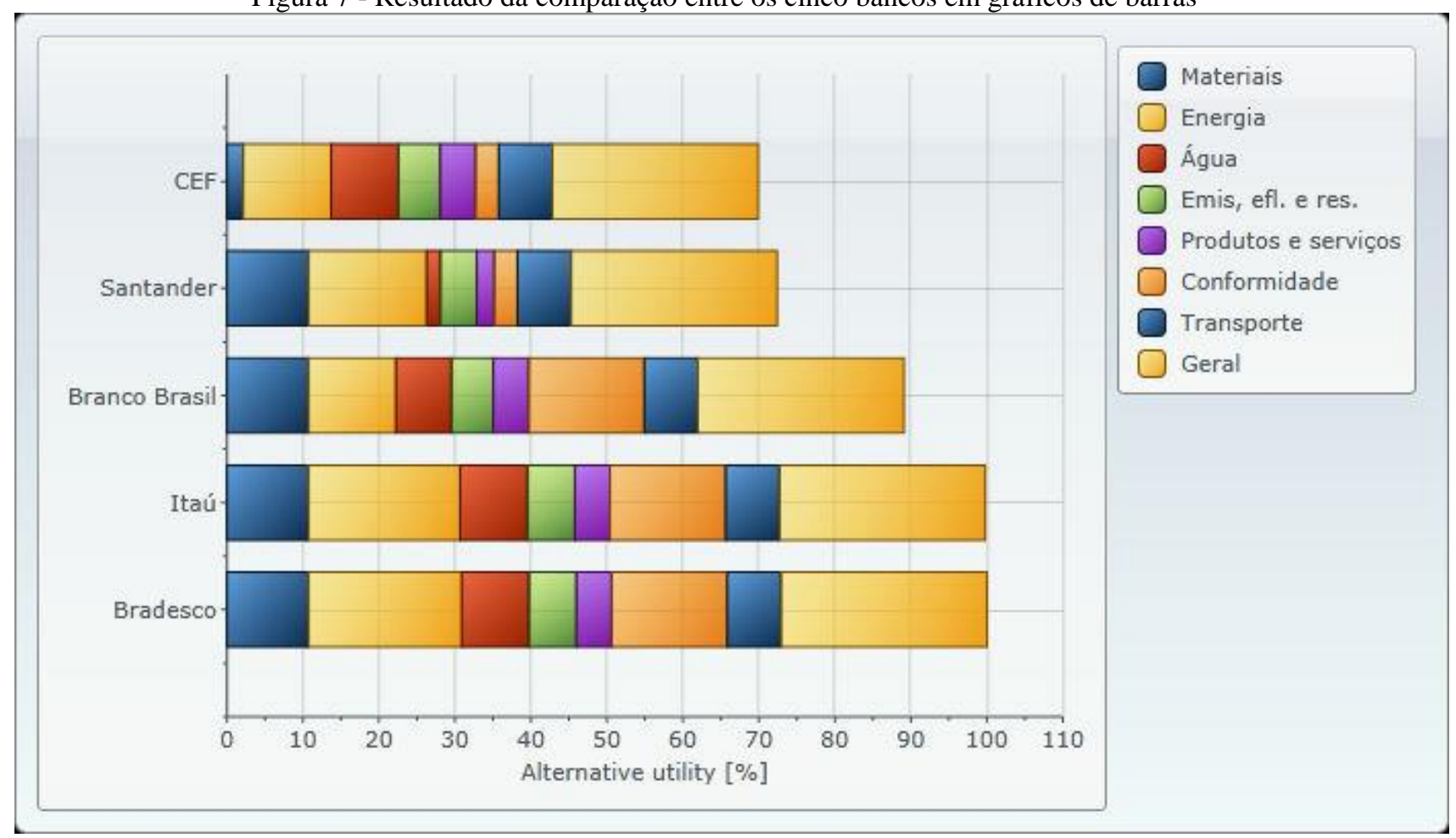

Fonte: Autoria própria (2014)

Tabela 6 - Resultados quantitativos complementares ao gráfico da Figura MMM

\begin{tabular}{|c|c|c|c|c|c|c|c|c|c|}
\hline Banco & $\begin{array}{c}\text { Total } \\
(\boldsymbol{\%})\end{array}$ & $\begin{array}{c}\text { Mater. } \\
(\boldsymbol{\%})\end{array}$ & $\begin{array}{c}\text { Energ. } \\
(\boldsymbol{\%})\end{array}$ & $\begin{array}{c}\text { Água } \\
(\boldsymbol{\%})\end{array}$ & $\begin{array}{c}\text { Emissões, } \\
\text { efluentes e } \\
\text { resíduos } \\
(\boldsymbol{\%})\end{array}$ & $\begin{array}{c}\text { Prod. } \\
\mathbf{e} \\
\text { serv. } \\
(\boldsymbol{\%})\end{array}$ & $\begin{array}{c}\text { Conform. } \\
(\boldsymbol{\%})\end{array}$ & $\begin{array}{c}\text { Transp. } \\
(\boldsymbol{\%})\end{array}$ & $\begin{array}{c}\text { Geral } \\
(\boldsymbol{\%})\end{array}$ \\
\hline Bradesco & 100,00 & 10,75 & 20,15 & 8,85 & 6,24 & 4,63 & 15,23 & 7,06 & 27,10 \\
\hline Itaú & 99,79 & 10,75 & 19,94 & 8,85 & 6,24 & 4,63 & 15,23 & 7,06 & 27,10 \\
\hline B. Brasil & 89,08 & 10,75 & 11,50 & 7,31 & 5,51 & 4,63 & 15,23 & 7,06 & 27,10 \\
\hline Santander & 72,39 & 10,75 & 15,55 & 1,80 & 4,78 & 2,31 & 3,05 & 7,06 & 27,10 \\
\hline CEF & 69,92 & 2,15 & 11,58 & 8,85 & 5,51 & 4,63 & 3,05 & 7,06 & 27,10 \\
\hline
\end{tabular}

Fonte: Autoria própria (2014) 


\section{Conclusões}

Este trabalho objetivou avaliar o desempenho ambiental relativo entre as cinco maiores instituições financeiras no Brasil que publicam seus relatórios de sustentabilidade de acordo com as diretrizes da GRI no período 2009 a 2012.

A avaliação de desempenho foi realizada com base nos indicadores ambientais propostos pelas Diretrizes para Relatório de Sustentabilidade GRI. Foram identificados inicialmente trinta indicadores de desempenho ambiental GRI, os quais são originalmente divididos em conjuntos afins denominados "aspectos". Depois de um trabalho de refinamento, constatou-se que doze indicadores não são aplicáveis ao setor financeiro devido ao tipo de serviço prestado. Os dados para a pesquisa foram coletados a partir dos relatórios de sustentabilidade divulgados por cada banco.

Os "aspectos" e os indicadores GRI foram ponderados considerando que existe uma dominância de um elemento sobre outro. Ou seja, no conjunto "aspectos" há alguns aspectos mais importantes do que outros, o mesmo valendo para os indicadores. Para isso aplicou-se o método AHP, o qual é interessante quando os elementos constituintes do processo de tomada de decisão são difíceis de quantificar ou comparar. A utilização do método AHP envolveu a sinopse matemática de várias arbitragens sobre o problema de decisão.

A comparação de desempenho relativo entre os bancos foi obtida com o desdobramento natural do métdo AHP. Deste modo, a questão central do AHP esteve calcada não apenas na determinação do peso com os quais os fatores individuais do nível mais baixo da hierarquia influenciaram o fator máximo, o objetivo geral. Mas também na avaliação confrontativa entre as cinco instituições bancárias sob a perspectiva de cada indicador GRI. E de cada um destes sob o ponto de vista de cada especialista.

O resultado da ponderação entre os critérios ou "aspectos" revelou que critério "geral" foi considerado o critério de maior importância relativa (27,10\%), seguido pelo critério "energia" (20,15\%), “conformidade" (15,23\%), “materiais" (10,75\%), “água” (8,85\%), "transporte” (7,06\%), “emissões, efluentes e resíduos" (6,24\%) e "produtos e serviços" (4,62\%).

Como resultado final, sob a ótica da equipe de especilistas estabelecida, o Banco Bradesco foi o banco classificado em primeiro lugar com desempenho ambiental relativo de 100\%; seguido pelo Banco Itaú, com desempenho ambiental relativo de 99,79\%; Banco do Brasil com desempenho relativo de 89,08\%; Banco Santander, com desempenho relativo de 72,39\%; e último lugar a CEF com desempenho relativo de $69,92 \%$. Conclui-se que os cinco principais bancos brasileiros possuem desempenho ambiental relativo que pode ser avaliado qualitativamente entre "bom" a "muito bom". 


\begin{abstract}
The objective of this work is to present a comparative evaluation of the environmental performance of five major Brazilian banks in the period between the years 2009-2012. For this performance evaluation was used as environmental indicators those proposed by the Sustainability Reporting Guidelines "Global Reporting Initiative" (GRI). Among the thirty environmental performance indicators initially identified, it was found that twelve of them are not applicable to the financial sector due to the type of service provided. Data for the study were collected from the sustainability reports published by each bank. The applicable GRI indicators were weighted using the Analytic Hierarchy Process (AHP) method, whereas there is a dominance of one element over another. The judgment required the AHP method were performed by a team of experts from two public universities in State of São Paulo. The consistency test showed that the values attributed to the relative priorities of indicators can be considered consistent. As a final result, from the perspective of experts team established, the Banco Bradesco was the bank ranked first in environmental performance of $100 \%$. In the second place is Banco Itaú, with relative environmental performance of $99.79 \%$. Thirdly, the Banco do Brazil with relative performance of $89.08 \%$. In fourth position is the Banco Santander with relative performance of $72.39 \%$. And in fifth and last place is CEF with relative performance of $69.92 \%$. It is concluded that the five major Brazilian banks have the environmental performance ranging from "good" to "very good."
\end{abstract}

Key-words: environmental development; environmental indicators; banks; method; Analytic Hierarchy Process (AHP).

\title{
Referências
}

BANCO CENTRAL DO BRASIL. 50 maiores bancos e o consolidado do Sistema Financeiro Nacional. Disponível em: < http://www4.bcb.gov.br/top50/port/top50.asp>. Acesso em: dez. 2013.

BEAL, S. F. L. S. Desenvolvimento sustentável: responsabilização civil dos bancos. Ciências Sociais Aplicadas em Revista, v.11, Ed. Especial, p.217-235, 2011.

BISANG, O. A importância da certificação ISO 14001 para as instituições financeiras. Green Banking 2000. Disponível em: <http://www.qsp.org.br/biblioteca/green_banking.shtml> Acesso em: mar. 2014.

BLANK, D. M. P.; BRAUNER, M. C. C. A responsabilidade civil ambiental das instituições bancárias pelo rico ambiental produzido por empresas financiadas. Revista Eletrônica do Mestrado Educação Ambiental, v. 22, p. 261275, janeiro a julho de 2009.

CERVO, A. L.; BERVIAN, P. A. Metodologia científica: para uso de estudantes universitários. 3. ed. São Paulo: McGraw-Hill do Brasil, 1983.

CONAMA. Resolução Conama 01 de 23 de jan. 1986 - Estabelece as definições, as responsabilidades, os critérios básicos e as diretrizes gerais para uso e implementação de Impacto Ambiental como um dos instrumentos da Política Nacional do Meio Ambiente. Disponível em: <http://www.mma.gov.br>. Acesso em: jan. 2014.

FEBRABAN. Terrenos contaminados impactam financiamentos bancários. Pronunciamentos. 2013. Disponível em: <http://www.febraban.org.br/Noticias1.asp?id_texto=2007>. Acesso em: fev. 2014.

GRI. Diretrizes para Relatório de Sustentabilidade. 2006. Disponível em:

<https://www.globalreporting.org/resourcelibrary/Brazil-Portuguese-G3-Reporting-Guidelines.pdf>. Acesso em: mar. 2014.

INFANTE, C. E.; CANTANHEDE, I. L.; VALLE, R.; MENDONÇA, F. M. A Inovação da Sustentabilidade nos Bancos Brasileiros e Internacionais. INGEPRO - Inovação, Gestão e Produção, v. 2, n. 11, p. 038-047, 2010.

LINS, C.; WAJNBERG, D. Sustentabilidade corporativa no setor financeiro brasileiro. Fundação Brasileira para o Desenvolvimento Sustentável. 2007. Disponível em: 〈http://fbds.org.br/IMG/pdf/doc-243.pdf〉. Acesso em: jan. 2014. 
MATTARIZZI, V.; TRUNKL, C. Sustentabilidade no setor financeiro: gerando valor e novos negócios. São Paulo: Editora Senac São Paulo, 2008.

MERCADO COMUM. O Seguro Ambiental como mecanismo de minimização do passivo ambiental das empresas. Disponível em: <http://www.mercadocomum.com/site/artigo/detalhar/o-seguro-ambiental-comomecanismo-de-minimizacatildeo-do-passivo-ambiental-das-empresas >. Acesso em: jan. 2014

NAVES, R. M. Análise hierárquica de sistema de bilhetagem eletrônica. Rio de Janeiro, 2008. 96p. Dissertação (Mestrado em Engenharia de Transportes). Universidade Federal do Rio de Janeiro, COPPE.

OLIVEIRA, A. A.; COSTA, J. A. F.; NETO, M. V. S. Aplicação do método de análise hierárquica na tomada de decisão para a adoção de computação em nuvem. In: SIMPOI, 2011. São Paulo: FGV-EAESP, 2011.

PORTAL BRASIL Cresce o número de municípios no Brasil. Disponível em: < http://www.brasil.gov.br/economiae-emprego/2013/06/cresce-numero-de-municipios-no-brasil-em-2013>. Acesso em: set. 2013.

SAATY, T. L. Creative thinking, problem solving and decision making. Pittsburgh: RWS Publications, 2010.

SAATY, T. L. Decision making for leaders: the Analytic Hierarchy Process for decisions in a complex world. Pittsburgh: RWS Publications, 2008.

SAATY, T. L. Método de Análise Hierárquica. São Paulo: Makron Books, 1991.

SANTOS, C. F. F.; OLIVEIRA, E. G. F.; ALKIMIM, H. R. M.; LEITE, J. G.; SILVA, M. G.; ALVES, T. C.; CARVALHO, V. A.; ARAÚJO, V. G. A importância dos bancos públicos na economia brasileira. Centro Universitário UNA. 2010. Disponível em: <http://www.youblisher.com/p/72827-A-Importancia-das-Instituic-esBancarias-na-Economia-Brasileira/>. Acesso em: jan. 2014.

SEADE. Bancos. Ministério da Educação. Brasil. Disponível em:

<http://portal.mec.gov.br/setec/arquivos/pdf1/bancos.pdf>. Acesso em: jan. 2014.

SHIMIZU, T. Decisão nas organizações. $3^{\text {a }}$ Ed. São Paulo: Atlas, 2010.

SMALL, D. Playing it safe: areas of focus for safety compliance. Ethanol Producer Magazine. June, 2008. Disponível em:<http://www.ethanolproducer.com/articles/4285/playing-it-safe-areas-of-focus-for-safety-compliance>. Acesso em: jan. 2014.

TOSINI, M. F. C. Risco ambiental para as instituições financeiras. São Paulo: Annablume, $2006 \mathrm{a}$.

TOSINI, M. F. C. Risco ambiental para as Instituições financeiras bancárias. Boletim Responsabilidade Social e Ambiental do Sistema Financeiro. Ano 1, n.2 Janeiro 2006 b.

TOSINI, M. F. C. Risco ambiental para as Instituições financeiras bancárias. Campinas, 2005. 157p. Dissertação (Mestrado em Desenvolvimento Econômico, Espaço e Meio Ambiente). Instituto de Economia, UNICAMP.

\section{Dados dos autores}

Nome completo: Marcelo Giroto Rebelato

Filiação institucional: FCAV - UNESP - Jaboticabal

Departamento: Economia Rural

Endereço completo para correspondência (bairro, cidade, estado, país e CEP): Via de Acesso Prof.

Donato Castellane s/n - 14884-900 - Jaboticabal - SP

e-mail:mgiroto@fcav.unesp.br

Nome completo: Amanda Zampieri de Almeida 
Filiação institucional: FCAV - UNESP - Jaboticabal

Endereço completo para correspondência (bairro, cidade, estado, país e CEP): Via de Acesso Prof.

Donato Castellane s/n - 14884-900 - Jaboticabal - SP Telefones para contato: 1632026519

e-mail: amanda_zalmeida@hotmail.com

Nome completo: Andréia Marize Rodrigues

Filiação institucional: FCAV - UNESP - Jaboticabal

Departamento: Economia Rural

Endereço completo para correspondência (bairro, cidade, estado, país e CEP): Via de Acesso Prof.

Donato Castellane s/n - 14884-900 - Jaboticabal - SP

e-mail: andreiamarize@fcav.unesp.br

Submetido em: 24/03/2014

Aceito em: 18/12/2014 